\title{
Education, digital literacy and democracy: the case of Britain's proposed 'exit' from the European Union (Brexit)
}

\author{
Kenneth King ${ }^{1}$
}

Received: 25 April 2019 / Revised: 26 April 2019 / Accepted: 30 April 2019 / Published online: 29 May 2019

(C) The Author(s) 2019

\begin{abstract}
There has been a long tradition of demonstrating formal education's direct relationship with many dimensions of development, including increased productivity, health, reduced mortality, population control etc. There has also been a literature looking particularly at the 'democratic dividend' from education, both through the lens of global citizenship as well as more generally through education's influence on political participation. The successful securing of global citizenship education (GCE) within the ambitions of Sustainable Development Goal 4.7 in September 2015 was a further milestone in connecting social development with 'democracy, good governance and the rule of law'. Accordingly, there are many telling examples of how GCE can be rolled out in school curricula, through many different school subjects, across the world. Arguably, however, the formal school system is far from being the only location where messages about citizenship, whether global, national or local, can be found. During the period, 2016-2019 in the USA and UK, with the huge rise in smart-phone usage world-wide, it has become apparent that there can be massive micro-targeting, through global platforms, of selected populations with multiple messages about citizenship, national identity, job security, migration threats, potential terrorism and a great deal else. Unlike the citizenship curricula and textbooks of formal schools which are easily accessible, a great deal of this new social media messaging is relatively inaccessible, using procedures that are a long way from traditional electioneering. They are also much less financially accountable, but it is clear that vast sums are now being spent on social media advertising, presenting an existential threat to democracy. The role and level of education in reacting critically to social media campaigning will need to be revisited in this new world of campaigning around global and national citizenship. It is no longer a discussion about education's positive relationship with increased political participation, but whether current education levels are actually capable of dealing with the current threats to citizenship, at global, national and local levels.
\end{abstract}

Keywords Brexit · Digital literacy $\cdot$ Disinformation $\cdot$ Fake news $\cdot$ Social media $\cdot$ Global Citizenship Education $\cdot$ Sustainable Development Goals

\section{Introduction}

There has been a long tradition ${ }^{1}$ of discussing formal education's direct relationship with many dimensions of development, including good governance, increased productivity, health, reduced mortality, population control and much else (UNESCO 2002, Ch. 1). There has also been a literature looking particularly at the 'democratic dividend' from education, both through the lens of global citizenship as well as more generally through education's influence on political

Kenneth King

Kenneth.King@ed.ac.uk

1 School of Social and Political Science, University of Edinburgh, Edinburgh, UK participation (King 2019b). The successful securing of global citizenship education (GCE) within the ambitions of Sustainable Development Goal (SDG) 4.7 in September 2015 was a further milestone in connecting social development with 'democracy, good governance and the rule of law' (UN 2015, Para.9). Accordingly, there are many telling examples of how GCE can be rolled out in school curricula, through many different school subjects, across the world (Sang Saeng 2018: 50).

Arguably, however, the formal school system is far from being the only location where messages about citizenship, whether global, national or local, can be found. During the period, 2016-2019, in the USA and UK, with the huge rise

\footnotetext{
${ }^{1}$ More than 100 years ago (1916), John Dewey published Democ-
} racy and Education, Macmillan, New York. 
in smart-phone usage world-wide, it has become apparent that there can be massive micro-targeting, through global platforms, of selected populations with multiple messages about citizenship, national identity, job security, migration threats, potential terrorism and a great deal else. Unlike the citizenship curricula and textbooks of formal schools which are easily accessible, a great deal of this new social media messaging is relatively inaccessible, using procedures that are a long way from traditional electioneering techniques. They are also much less financially accountable, but it is clear that vast sums are now being spent on social media advertising, presenting an existential threat to democracy, according to the UK's cross-party Committee on Digital, Culture, Media and Sport (DCMS 2018a, 2019).

The episode which is described in greater detail below is just a tiny illustration of what is being termed 'surveillance capitalism' in the words of Zuboff:

It works by providing free services that billions of people cheerfully use, enabling the providers of these services to monitor the behaviour of those users in astonishing detail - often without their explicit consent. 'Surveillance capitalism', she writes, 'unilaterally claims human experiences as free raw material for translation into behavioural data. Although some of these data are applied to service improvement, the rest are declared as a proprietary behavioural surplus, fed into advanced manufacturing processes known as 'machine intelligence', and fabricated into prediction products that anticipate what you will do now, soon, and later. (Naughton on Zuboff 2019: 17)

The role and level of education in reacting critically to social media campaigning will need to be revisited in this new world of campaigning around global and national citizenship. It is no longer a discussion about education's positive relationship with increased political participation, but whether current education levels are actually capable of dealing with the contemporary threats to citizenship, at global, national and local levels.

The paper starts, however, by interrogating the apparently critical role of education in the two recent votes-in Britain's European Union Referendum in 2016, and, in passing, in the Trump election in 2017. It does so against the background literature on education and democracy.

But first a word on methodology is in order. Brexit has dominated Britain's media discourse since June 2016 when the Referendum took place. Because there was no government precaution to ensure that there should be a minimum majority such as $60 \%$ for the Referendum to be binding, the actual percentages of $51.9 \%$ for Leave and $48.1 \%$ for Remain made it difficult to claim there was a clear decision to leave. The notion of 'honouring the Referendum' or 'the will of the people' was made more complex when it became clear that Scotland had voted to remain by the significant margin of $62 \%$ and Northern Ireland by $55.8 \%$. Only Wales (52.5\%) and England (53.4\%) had actually voted by a majority to leave the European Union (BBC News 2019).

This relatively small margin for Leave in the UK as a whole is made hugely more problematic by the role of misinformation and fake news, particularly on the Leave side. The possibility that a significant number of people were persuaded to vote Leave because of the influence of the illegal advertising discussed in this paper makes for a new meaning of 'democratic deficit'.

Other dimensions of democracy connecting with Brexit over the month of March 2019 were the march by over a million people in London on the 23rd to request a second referendum on Britain's relationship with the European Union. Another initiative, even larger, was the petition to the UK Parliament to 'Revoke Article 50 and remain in the EU'. ${ }^{2}$ This petition secured unprecedented support in just a few days. Almost six million signatures were secured in this period; but the Government turned down the petition on the 26th March 2019, arguing it would 'disrespect the clear instruction from a democratic vote' (UK Government and Parliament 2019).

Methodologically, the increasing complexities of securing agreement on Brexit have been played out over the period of almost 3 years since the Referendum of June 2016. There has been a degree of polarisation between those voting Leave and Remain, but despite the mounting evidence of the economic disadvantages of leaving the EU, there is not much evidence of voters substantially changing their minds. It was estimated in 2018, however, that $52 \%$ of the electorate would vote to remain and only $48 \%$ vote to leave. And in the latest British Attitudes Survey data in March 2019, it appears that $55 \%$ of the voters would want to remain in the EU: "Brexit has ceased to be the "will of the people" and in a second referendum 55 per cent would vote Remain' analysis of British Social Attitudes Survey respondents has reported' Independent (2019).

Although there is a considerable literature on education and political socialisation (e.g. Prewitt 1971; McCowan 2012; O'Toole 2018), the impact of new forms of political influence via social media is much less common as the phenomenon has only been widely recognised in the period 2016-2019.

\footnotetext{
2 The petition read as follows: 'The government repeatedly claims exiting the EU is "the will of the people". We need to put a stop to this claim by proving the strength of public support now, for remaining in the EU.' UK Government and Parliament: https://petition.parli ament.uk/petitions/241584.
} 


\section{Education as a factor in the Brexit referendum and in the 2017 US election}

As already mentioned, there has been a good deal of discussion historically on the role of education in building democratic societies. In the lead up to the agreement on the Sustainable Development Goals, there was significant debate about the inclusion and measurement of democratic governance in the post-2015 accord (UNDP 2012). In the event, however, neither 'democracy' nor 'democratic' appear in the text of the 17 SDGs; nor does 'good governance'. The nearest we get to these is in the UN's introductory text to the SDGs where a future world is envisaged with certain characteristics: amongst these, a world 'in which democracy, good governance and the rule of law.... are essential for sustainable development' (UN 2015, para. 9).

Shortly before the SDGs were set in 2015, a whole chapter of the Global Monitoring Report (GMR) on Education for All of 2013/14 was dedicated to reviewing how 'Education transforms lives'. A crucial part of that chapter was concerned with education's 'key role in promoting democratic values' (UNESCO 2014: 170). Intriguingly, though a good part of the argument is concerned to show that primary education confers more awareness of democratic values than no education, and secondary education more than primary, there is no discussion of whether higher education is even more influential than primary or secondary in encouraging and improving political knowledge. What is said, importantly, is that it is not so much years of education as quality of that education that makes a difference:

The degree of political knowledge depends not only on the amount of time a child spends in school, but also on whether education is of sufficient quality to encourage key traits such as critical thinking (UNESCO 2014: 171).

Within Europe, furthermore, it is argued that years of schooling make a difference to political awareness:

Education improves knowledge about politics, as evidence from European countries shows: people who have four more years of schooling spend $50 \%$ more time, on average, acquiring information by reading newspaper articles on politics and current affairs (UNESCO 2014: 170). ${ }^{3}$.

What is not discussed at all in this kind of research is whether it matters to the creation of so-called democratic values what kind of newspaper articles on politics are read, not to mention other sources of political information

\footnotetext{
${ }^{3}$ The research does not sufficiently explore the meaning of 'four more years of schooling' in countries where the great majority of the population have received at least four years of secondary education.
}

received through social media. Nor is it discussed that the mass circulation tabloids in Europe and in the USA reach many more people than the so-called serious, broadsheet press. For instance, in the UK the tabloid, the Sun, has a circulation of 1.6 million readers whilst the Guardian has less than a tenth $(149,000)$. Equally, it may be the case in some countries that a great deal of the press supports conservative, right-wing values. This would arguably be true of the UK.

The GMR of 2013/2014 does however make a whole series of claims about the engagement of education with democracy and good governance. These are treated in several separate sections of chapter three:

Education builds the foundations of democracy and good governance.

Education improves political knowledge.

Education strengthens support for democracy.

Education raises political participation.

Education promotes tolerance and social cohesion.

Education helps prevent conflict and heal its consequences.

Education helps reduce corruption.

Education is essential for the justice system to function (UNESCO 2014, pp. 170-177).

We thus have something of a paradox when it comes to the role of this kind of policy research about education encouraging democratic values. The bulk of the British press, both serious and tabloid, has been supportive of Britain's leaving the European Union (Brexit). Yet the best evidence of the role of education in the Brexit referendum of June 2016, as contained in the British Social Attitudes (BSA) survey, is that a great majority of those with higher education voted to remain in the EU (78\%), whilst $72 \%$ of those without formal educational qualifications voted to leave the EU (BSA 2017: 7). There are similar results on the voting patterns of college-educated versus non-college educated whites in the 2016 Trump election (Pew 2018).

The research associated with the 2013/4 GMR was principally concerned with the role of basic education; hence its interest was to examine the difference in attitudes towards political participation and engagement by those with little or no education, those with primary and those with secondary. And its focus was more with this 'democratic dividend' in developing rather than developed economies. By contrast, the very great bulk of the electorates in Europe and North America in most countries has received compulsory secondary education of at least 4 years; so it is no longer a question of comparing those with no education, primary and secondary education. But rather the focus may be on the role of post-secondary versus secondary education, and on the outcomes of education such as formal qualifications and not merely on number of years of education. Hence the BSA 
of 2017 examined different levels of formal qualifications, from graduate, to full secondary, to lower secondary, and also those with no educational qualifications.

It was found that not only was there a sharp distinction in relation to Brexit, already reported above, between those with degrees versus those with no formal educational qualifications, but also that there were differences progressively between those with lower secondary and higher secondary qualifications.

Education level, however, was not the only factor examined by the BSA in relation to the vote on Brexit. It also noted the very strong influence of age. Thus, some $80 \%$ of 18-24-year-olds voted to remain in Europe whilst some 63\% of those who were $65+$ voted to leave the European Union. There was another dimension of age that was critical. The turnout of younger people (at 64\%) was much lower than those aged 35-64 (80\%) or those over 65 (89\%) (BSA, 34:6). Despite the lower turnout of young people, the combination of education with age merely confirmed the apparently crucial role of graduate level qualifications, and of course the proportion of the population with degrees increased amongst younger voters, given the spread of higher education in the last 20 years within the UK.

Clearly there is also a close connection between education and class; but in the Referendum vote, of those in professional and managerial jobs only $36 \%$ voted to leave, whilst $60 \%$ of those in routine and semi-routine jobs voted to leave. The resulting difference of 24 points is much less than the 50 point difference evident between graduates and those without any educational qualifications.

These bald figures say nothing about what it is about higher education that might encourage particular attitudes towards politics, but one possibility is that the extent of critical thinking tends to increase with level of education. Thus, the capacity to examine critically the manifestos and the advertisements of the Leave versus the Remain campaigns is presumably sharpened by higher education. On the other hand, the tendency actually to vote is often higher among older than younger people, and in the case of the June 23rd 2016 Referendum in the UK, it actually took place after the university summer term was over. Apparently, many younger people, including university students assumed that the vote would be unproblematically in favour of staying in Europe, and hence they did not bother to vote. In this respect, it would be intriguing to know the breakdown by age of that proportion of the electorate (almost 30\%) which did not actually vote. For instance, in the British General Election which took place in early June 2017, a much larger number of young people, including university students, voted, and not least as the election took place during the university summer term.

BSA 34 concluded on this issue as follows after reviewing relevant factors:
The pattern of voting in the EU referendum reflected then, above all, an educational divide. At one end of the spectrum most graduates voted to remain in the EU - at the other, most with few, if any educational, qualifications voted to leave (BSA 2017: 9).

The BSA 34 was far from being the only survey that analysed, amongst many other factors, the role of education in the Referendum vote. Some other surveys looked explicitly at the influence of education on the voting patterns in this crucial vote. Researchers in the University of Leicester claimed in a newspaper headline that 'Brexit caused by low levels of education' (Stone 2017). Like the BSA survey, they found that "whether someone had been to university or accessed other higher education was the "predominant factor" in how they voted' (Stone 2017). Given that the quantitative difference between Leave and Remain was just 1.2 million notes, the research argued that 'had just 3\% more of the population gone to university, the UK would probably not be leaving the EU' (Stone 2017). Like the BSA survey, the researchers found that: 'The level of higher education in an area was far more important than age, gender, the number of immigrants, or income in predicting the way an area voted' (ibid).

\section{The role of social media in political engagement}

The next section reviews some of the mechanisms that have relatively recently become available in electioneering in socalled democratic societies. They are a world away from the traditional electioneering of soap-boxes, door to door leafletting, and town-hall events. Instead, they involve algorithms that identify millions of social media users with particular profiles, by education, location, employment, age and other characteristics, and these can be targeted with very specific messages.

Arguably, social media played a very significant role in both the 2016 US and 2017 UK elections as well as in the EU Referendum in the UK (DCMS 2019). At the same time, there has grown to be an increasing concern with fake news and with disinformation in the UK and the USA. This has included allegations about Russian interference in the EU Referendum and US election, on the side of the Leave campaign and in support of Trump; ${ }^{4}$ but there has also been clear evidence of the use of Facebook data by Cambridge Analytica to support the micro-targeting of particular populations

\footnotetext{
4 There may well have been interference in the US elections even if there was no actual collusion with the Trump campaign. See further DCMS (2019), p. 68 ff; and Cadwalladr (2019).
} 
in the UK with propaganda in favour of leaving the EU (DCMS 2018a, Ch. 3). ${ }^{5}$

It was only in July 2018, two years after the EU Referendum of 2016, that the actual messages targeted at particular constituencies in the UK were handed over by Facebook at the insistence of the DCMS committee. Three examples of the many 'dark ads' used by the Vote Leave campaign are given here below (Cadwalladr 2018; BBC News 2018). These advertisements, masterminded by the Vote Leave could be targeted at areas where there is already a concern about migration from Europe. And it could be focused on non-professional social media users. This, and 23 other dark ads, were finally made public in July 2018 when Facebook handed over the material to the DCMS committee. 'It is an extraordinary and revelatory collection: a collection dominated by overtly racist lies-notably that Turkey's 76 million citizens were about to join the European Union'.

(Cadwalladr, 28th July, 2018).

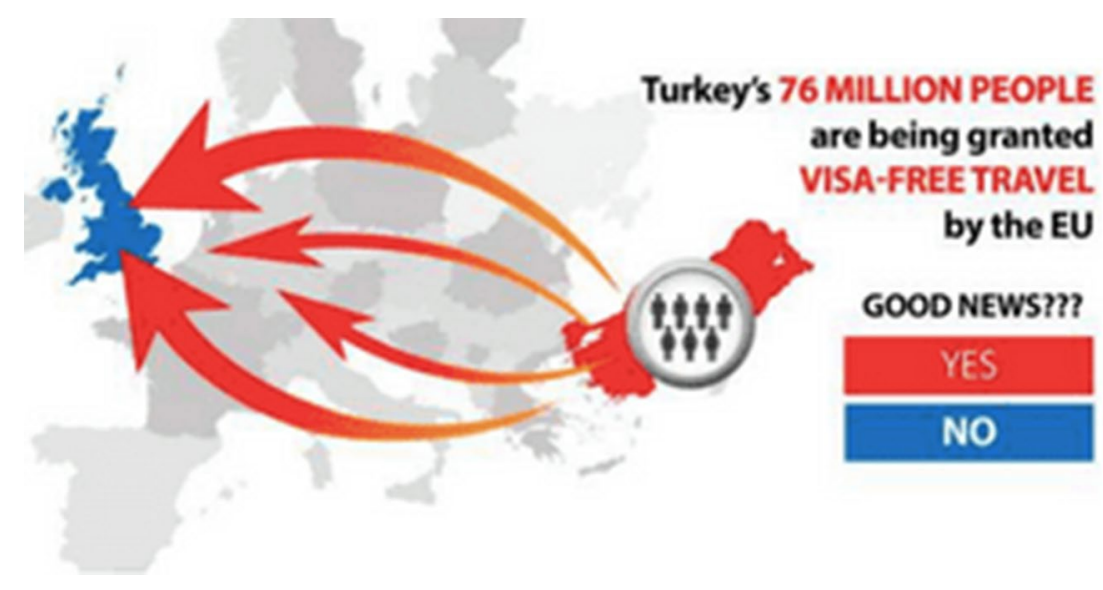

campaign through Facebook, were previously unseen by anyone other than those who had been anonymously targeted. Most of these were served in the critical final days of the campaign (ibid.). They are considered by the DCMS report as a key element in 'the relentless targeting of hyperpartisan views which play to the prejudices of people, in order to influence their behaviour' (DCMS 2018a: 26). ${ }^{6}$

One of these advertisements claimed that 'Turkey's 76 million people are being granted visa-free travel by the EU. Good News? Yes.... No' (emphasis in original). The four arrows on the advertisement all point from Turkey towards the UK. Such an advertisement would be aimed at constituencies that are not aware of the many political challenges to Turkey's membership of the European Union. Indeed, there are no plans for Turkey to join the EU. But the advertisement

\footnotetext{
5 Chapter 3 of the DCMS report of 2018a has the following title: 'The issue of data targeting, based around the Facebook, GSR and Cambridge Analytica allegations'.

6 The politics and processes of the Vote Leave campaign were vividly demonstrated in a Channel 4 film of 7th January 2019 called 'BREXIT: the uncivil war' with actor Cumberbatch in the lead role of Cummings, the Vote Leave strategist. See https://www.channel4.com/ programmes/brexit-the-uncivil-war.

Despite the furore about this micro-targeting, it has continued in the UK by new Facebook advertisements about Brexit whose sponsors and financing are deliberately obscure (Waterson 2019).
}

No fewer than 24 advertisements were targeted at British voters in the last few days of the Referendum campaign. They were seen at least 1.9 million times and possibly as many as 4.2 million times (BBC News 2018). ${ }^{7}$ The Final Report of the DCMS confirmed the wider and longer scale of the targeting: 'According to Facebook, "AIQ ran 1390 ads on behalf of the pages linked to the referendum campaign between February 2016 and 23 June inclusive" (DCMS 2019: 45).

Older voters tended to be treated to claims about how much money the UK was sending to the EU. More than 140 repeated ads made reference to the controversial claim that $£ 350$ million a week was sent to the EU and could be spent on the NHS instead. The text of one of these read: 'Every week we send $£ 350$ MILLION TO THE EU. Enough to build a new NHS hospital every 7 days. Click to help the NHS' [emphasis in the original]. Alternative uses for the $£ 350$ million included schools.

\footnotetext{
7 The larger set of messages secured from Facebook, many of explicitly pro-Brexit, were seen 169 million times (BBC News 2018).
} 
Every week we send

$£ 350$ MILLION TO THE EU

Enough to build a new

NHS hospital every 7 days

CLICK TO HELP THE WHS

There was one advertisement featuring Jeremy Corbyn, Leader of the Opposition in the UK Parliament, which was targeted at younger voters and accompanied by an old quote from the Labour leader: "The EU takes away from national parliaments the power to set economic policy and hands it

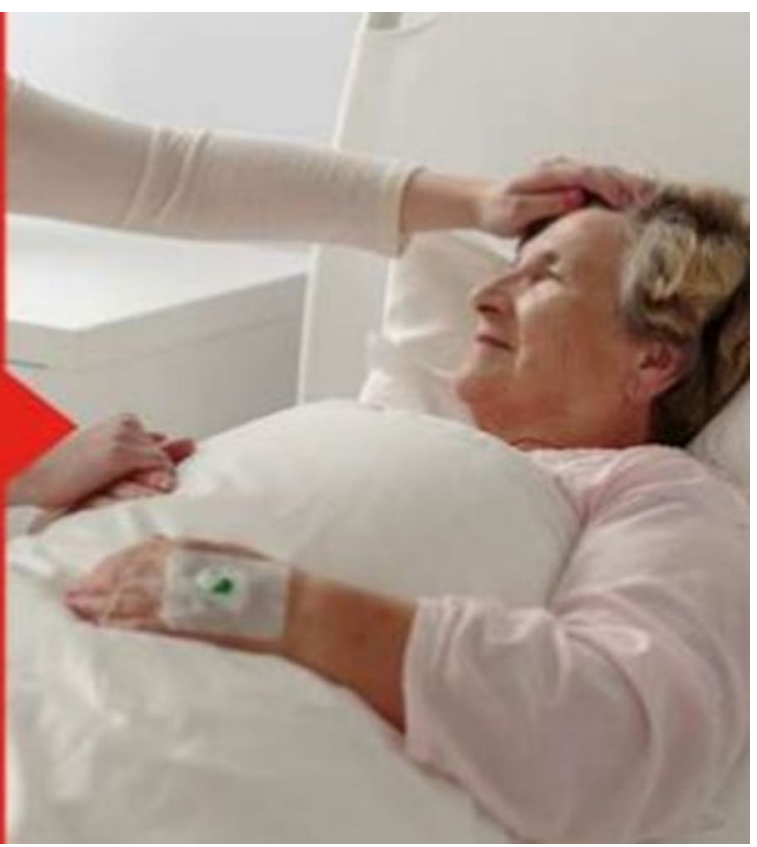

over to an unelected set of bankers." (BBC News, https:// www.bbc.com/news/uk-politics-44966969) It continued 'I AGREE WITH CORBYN ON THE EU. Yes No' (emphasis in the original).

\section{AGREE WITH} CORBYN ON THE EU 
Beyond these data secured by the DCMS about mass messaging before the Referendum vote in the UK, there is abundant evidence of the tie-ups between Cambridge Analytica, Steve Bannon of Breitbart News in the USA, and different elements of the Vote Leave campaigns (DCMS 2018a: 27). The former chief executive of Cambridge Analytica, Alexander Nix, has claimed the following, including an allegation about the value of their interventions for democracy:

We are trying to make sure that voters receive messages on the issues and policies that they care most about, and we are trying to make sure that they are not bombarded with irrelevant materials. That can only be good. That can only be good for politics, it can only be good for democracy and it can be good in the wider realms of communication and advertising (DCMS 2018a: 27).

As far as the implications for democracy are concerned, this is seen by the DCMS committee to be a central outcome of their 18 months' investigation of disinformation. It leads their report to underline the substantial educational implications of the operation of social media content:

If we are talking about news and media literacy curricula, that has to include how to evaluate an algorithm and how to understand how what you see on Amazon, Netflix or Facebook has been decided by an algorithm, how an algorithm gets developed, how it is created by a certain person and how their biases might shape that. That has to be part of the teaching that we give to people (quoted in DCMS 2018a: 61).

Beyond the regular education curriculum for young people, it has been powerfully argued that because no less than $95 \%$ of 15-year-olds in the UK use social media before or after school, 'Digital literacy should become the fourth pillar of education, alongside reading, writing and maths' (DCMS 2018a: 63$)^{8}$

The sheer spread and influence of fake news and disinformation have become so significant that the DCMS committee recognized these factors to be a potential threat to democracy and values; indeed it was seen to be a phenomenon threatening the very future of democracy. The conclusion of their 89-page report is stark: 'Our democracy is at risk, and now is the time to act to protect our shared values and the integrity of our democratic institutions' (DCMS 2018a: 3). Critical, digital education is seen to be central to any solution. This is of course a challenge not only to schools but to adult education at a time when the budgets of

\footnotetext{
${ }^{8}$ Although the government response to the DCMS (2018a) turned down this recommendation (DCMS 2018b), it was reaffirmed in the DCMS final report (2019: 87).
}

bodies like the Workers Education Association (WEA) are under threat.

There is one other dimension of disinformation and its impact on democracy that needs to be noted. Since the difference between those voting to Leave or Remain was so small-at just 1.2 million votes out of total of 33.5 million, it is entirely possible that the massive investment in micro-targeting of millions of individuals through the mechanisms we have discussed could have made a difference. Interestingly, since the DCMS report on disinformation was released, it has been debated very much less in the UK than the Mueller inquiry on possible Russian interference in the US presidential election. Instead, there has been a constant refrain about 'the will of the people', or the 'British people voted to leave' in the Referendum of June 2016, without due recognition either of the possibility that some of the votes were manipulated, or that the British people could change their minds.

Intriguingly, there has been a resistance by the governing Conservative Party to the proposal that the 2016 referendum could be re-run on the grounds that that would be anti-democratic, but the government has sought to bring their same 'deal' back to the House of Commons several times without recognising the parallel. ${ }^{9}$

Given that there has been a flood of information about the consequences of leaving, with or without a deal, and of staying, it can be assumed that the electorate is now better informed. However, that again returns to our central topic of education and political awareness. To what extent has the total electorate of 46 million in the UK sought to learn about or educate themselves on the pros and cons of leaving and remaining?

\section{The global dimension of disinformation}

Though our concern so far has been principally with disinformation and the links between education and democracy in the UK, we must recognize that the manipulation of election processes through social media interventions has developed a global reach in recent years. Russia has already been mentioned for its possible involvement with both the UK's EU referendum and the 2017 US election. There is also evidence that Strategic Communications Laboratories (SCL) through its subsidiary, Cambridge Analytica, have been involved in elections and referenda campaigns in Kenya, Ghana, Mexico, Brazil, Australia, Thailand,

\footnotetext{
9 The prime minister's 'deal' was presented twice to the House of Commons in early 2019; there was a third attempt to bring the same deal back, but this was prevented by the Speaker of the House on the grounds that the same deal could not be continually presented to the House unless it was substantially altered from the first and second times.
} 
Pakistan, Philippines, Germany, England, Slovakia, Czech Republic and Kosovo. Other locations would include France, Guyana, Gambia, Italy, Malaysia, Niger, Nigeria, Peru, and St. Kitts (DCMS 2018: 54). This gives the manipulation of voting a thoroughly global dimension. It may, therefore, be appropriate to consider the preparation of young people to deal with these kinds of interventions to be a highly appropriate aspect of global citizenship education.

\section{Global citizenship education (GCE) and digital literacy for democracy}

GCE has been promoted by the former Secretary General of the UN through the Global Education First Initiative (GEFI), as well as through the UNESCO Centre for Education in International Understanding (APCEIU). These sources cover a good deal of the ground on GCE, and in particular the GEFI site notes that much of the existing curricula of schools by no means promotes good citizenship and international understanding. Rather, these are said to 'reinforce stereotypes, exacerbate divisions, and engender fear and resentment of other groups and nationalities' (http://www.globaleducation first.org/220.htm). GEFI continues with further critical assessment of the current situation: 'The values of peace, human rights, respect, cultural diversity and justice are often not embodied in the ethos of schools. Instead of empowering students to learn and thrive, schools often replicate social inequalities and reinforce social pathologies ....' (http://www. unesco.org/new/en/gefi/priorities/global-citizenship/).

Our present concern goes beyond acknowledging these curricular challenges to accepting diversity towards a worry about whether schooling provides the essential toolkit to deal critically with the prevalence of social media messaging, including messages that are biased or even untrue. The ambitions of GCE are clear and are well illustrated in Tawil's account of at least four sets of global concerns: human rights issues; environmental issues; issues of social and economic justice; and intercultural issues (Tawil 2013: 2). In dealing with these, there is no doubting the capacity of young people to use very readily their digital literacy to engage with social media. But their facility in using the technologies for social networking is very different from a critical capacity to sift out the truth from different forms of disinformation. The challenge of digital literacy is different again with older generations; in the case of 55 to 65 -yearolds in industrialised countries, allegedly only one in ten have the necessary digital skills effectively to manage digital information (UNESCO 2017: 7).

This could suggest that young people might be more susceptible to being targeted by the kinds of algorithms we discussed earlier. But with both younger and older people, the quality of their formal and non-formal education will prove to be a crucial element in their capacity to deal with both information and disinformation. If schools and their curricula can actually operate in the way that GEFI alleges, as noted above, then they may also be part of the problem.

We are left with a somewhat complex set of relationships when it comes to unravelling education's connections with democratic values. On the one hand, we noted that young people who had been encouraged to reach and finish college were very largely in favour of staying in the European Union, while those who, for whatever reason, had not managed to gain any formal qualification through school, voted overwhelmingly to leave the EU. It could well be that those failing to get any qualifications were in poorer quality schools, thus reinforcing the social inequalities allegedly associated with schooling. Such young people, who have not benefited from their schooling, at least in terms of certification, are nevertheless technically literate digitally as they possess and use smart phones for social media. But they may not be sufficiently digitally and critically literate to deal with fake news and disinformation. Hence they may become one of the target audiences for the algorithms against the EU, against migrants and much else.

On the other hand, we cannot talk naively about so many years of education automatically making a difference to democratic values, or to good or poor quality schooling having particular effects. After all, those creating disinformation and fake news are probably all college-educated, and may well have attended some of the top schools and universities in the country.

The key determinant of democratic awareness is thinking critically about information and knowledge. And such an approach is probably inseparable from good and committed teachers, and a supportive family environment. Though it is accepted that students only need a single committed and inspiring teacher to change their whole attitude towards education and achievement, it remains the case that millions of children and young people do not encounter a good school or even one good teacher (World Education Blog 2018).

Despite the vital importance of both committed teaching and a supportive family to the emergence of critical thinking or what may be called critical digital literacy, even those must depend on a wider, enabling participatory, political environment. The school and the family alone will not be sufficient. This parallels the World Bank research claiming that four years of education made a difference to agricultural productivity. It underlined the fact that the difference was crucially dependent on a wider enabling environment (King 2019a: 150ff). Similarly, the notion that education makes a difference to democratic engagement must depend on a wider environment supportive of that.

In this short paper, we have particularly focused on the role of education in encouraging democratic engagement, 
but we have reached a provisional conclusion that the school on its own, however good, may not be able to deliver this. Digital literacy cannot be acquired through the school alone. One of the dangers of the 17 Sustainable Development Goals (SDGs) is that it is tempting to read each one as self-contained and self-standing. Thus, SDG Target 4.7 (on Education) underlines a hugely ambitious agenda for education to deliver knowledge and skills, including on global citizenship:

4.7 By 2030, ensure that all learners acquire the knowledge and skills needed to promote sustainable development, including, among others, through education for sustainable development and sustainable lifestyles, human rights, gender equality, promotion of a culture of peace and non-violence, global citizenship and appreciation of cultural diversity and of culture's contribution to sustainable development (UN 2015: 17)

This edu-centric view of the facilitating role of education on its own is corrected by the UN's (2015) overall account Transforming our world: The 2030 agenda for sustainable development. This statement of the wider 2030 agenda makes it clear that all the sectoral dimensions of sustainable development are dependent on an enabling good governance and democratic environment. In the only use of the terms democracy in the whole document for the 2030 agenda, the UN specifies that social development (which would include education) has to depend on wider elements being in place:

[a world] in which democracy, good governance and the rule of law, as well as an enabling environment at the national and international levels, are essential for sustainable development, including sustained and inclusive economic growth, social development, environmental protection and the eradication of poverty and hunger (UN 2015: 4).

Open Access This article is distributed under the terms of the Creative Commons Attribution 4.0 International License (http://creativeco mmons.org/licenses/by/4.0/), which permits unrestricted use, distribution, and reproduction in any medium, provided you give appropriate credit to the original author(s) and the source, provide a link to the Creative Commons license, and indicate if changes were made.

\section{References}

BBC News. (2018). Vote Leave's targeted Brexit ads released by Facebook. Retrieved October 1, 2018 from https://www.bbc.com/news/ uk-politics-44966969

BBC News. (2019). EU referendum results. https://www.bbc.co.uk/ news/politics/eu_referendum/results. Accessed 9 May 2019
British Social Attitudes (BSA). (2017). The vote to leave the EU. London: National Centre for Social Research.

Cadwalladr, C. (2018). 'Plucky little panel' that found the truth about fake news, Facebook and Brexit, Guardian, 28 July 2018. Retrieved October 1, 2018 from https://www.theguardian.com/ politics/2018/jul/28/dcms-committee-report-finds-truth-fakenews-facebook-brexit

Cadwalladr, C. (2019). 'Mueller's report is a warning. And Britain won't listen'. Observer (London). Retrieved March 31, 2019.

DCMS (Digital, Media, Culture and Sport Committee). (2018a). Disinformation and 'fake news': Interim report, 24th July 2018. London: House of Commons.

DCMS (Digital, Media, Culture and Sport Committee). (2018b). Disinformation and 'fake news': Interim report: Government response to the Committee's fifth report of session 2017-2019. London: House of Commons.

DCMS (Digital, Media, Culture and Sport Committee). (2019). Disinformation and 'fake news': Final report, 14th February 2019. House of Commons, London.

Independent. (2019). Brexit: Political will of the people "must be in question" as 55 per cent now want to stay in the EU, poll finds. Retrieved March 26, 2019 from https://www.independent.co.uk/ news/uk/politics/brexit-will-of-people-poll-leave-remain-eu-secon d-referendum-vote-centre-social-research-curtice-a8839996.html

King, K. (2019a). Education, skills and international cooperation: Comparative and historical perspectives. Dordrecht, Comparative Education Research Centre (CERC) the University of Hong Kong, and Springer

King, K. (2019b). Education, global citizenship and democracy. In N. V. Varghese and M. Bandyopadhyay (Eds.) Post-2015 landscapes in democracy, education and development: Issues relating to inclusion, equity and sustainability. New Delhi, NUEPA

McCowan, T. (2012). Opening spaces for citizenship in higher education: Three initiatives in English universities. Studies in Higher Education, 37(1), 51-67.

National Centre for Social Research. (2018). ' $52 \%$ of Brits currently want to remain in the European Union, with $48 \%$ backing Leave', Poll of Polls. Retrieved March 27, 2019 from http://www.natce n.ac.uk/news-media/press-releases/2018/september/new-poll-ofpolls-tracker-shows-52-remain-and-48-leave/

Naughton, J. on Zuboff, S. (2019). Surveillance capitalism: The fight for the future at the new frontier of power. In Observer: The new review (pp. 16-21)

O' Toole, F. (2018). Heroic failure: Brexit and the politics of pain. London: Head of Zeus.

Pew Research Centre. (2018). 'An examination of the 2016 electorate, based on validated voters', $9^{\text {th }}$ August 2018 . Retrieved March 27, 2019 from https://www.people-press.org/2018/08/09/ an-examination-of-the-2016-electorate-based-on-validatedvoters/

Prewitt, K. (1971). Education and political values: An East African case study. Nairobi: East African Publishing House.

Saeng, Sang. (2018). Global citizenship education in local contexts, Special 50th issue. Seoul: APCIEU.

Stone, J. (2017). 'Brexit caused by low levels of education, study finds', 7 August 2017. Independent, London. Retrieved January 25, 2019 from https://www.independent.co.uk/news/uk/politics/ brexit-education-higher-university-study-university-leave-euremain-voters-educated-a 7881441.html

Tawil, S. (2013). Education for 'global citizenship': A framework for discussion. Working Paper 7, Education Research and Foresight. Paris, UNESCO

UK Government and Parliament. (2019). 'Revoke Article 50 and remain in the EU', Petitions. https://petition.parliament.uk/petit ions/241584 
UN. (2015). Transforming our world: The 2030 Agenda for sustainable development. New York, United Nations

UNDP. (2012). Measuring democracy and democratic governance in a post-2015 development framework, discussion paper. New York: UNDP.

UNESCO. (2002). Education for all: Is the world on track? EFA global monitoring report. Paris: UNESCO.

UNESCO. (2014). Teaching and learning: Achieving quality for all. EFA Global Monitoring Report, 2013/4. Paris, UNESCO

UNESCO. (2017). 'Literacy in a digital world', Summary, 8th September 2017. Paris, UNESCO. Retrieved October 5, 2018 from https ://en.unesco.org/sites/default/files/ild-2017-summary_of_discu ssions-en.pdf
Waterson, J. (2019). “"Grassroots” Facebook campaigns secretly run by Lynton Crosby staff'. The Guardian, 4th April 2019, p. 1 and 8. World Education Blog. (2018). A good education can change anyone. A good teacher can change anything. Global Education Monitoring Report, 5th October 2018. Retrieved October 6, 2018 from https://gemreportunesco.wordpress.com/2018/10/05/a-goodeducation-can-change-anyone-a-good-teacher-can-change-anyth ing/\#more-11981

Publisher's Note Springer Nature remains neutral with regard to jurisdictional claims in published maps and institutional affiliations. 